\title{
PROCEDIMENTOS DE ANÁLISE DE DISCURSO EM ROMANCE
}

\author{
Aloísio de Medeiros Dantas *
}

\begin{abstract}
Resumo: Este artigo apresenta inicialmente um trabalho de textos da Análise de Discurso, especificamente sobre a temática dos procedimentos analíticos. Recorrerá à leitura de textos de Eni Orlandi, por esta autora se constituir numa estudiosa dos conceitos de Michel Pêcheux, como formação discursiva (FD), interdiscurso, sujeito, interpretação e por ter figurado como uma das fundadoras do que se denomina Análise de Discurso, que aparece como disciplina em diferentes programas de pós-graduação e alguns cursos de graduação, no Brasil. Em seguida à resenha, ilustramos o procedimento analítico com uma pequena análise de um discurso paralelo, constituinte do romance A mulher que fugiu de Sodoma, de José Geraldo Vieira.
\end{abstract}

Palavras-chave: Procedimentos analíticos. Discurso. Romance.

Abstract: This article presents a review of the analytical procedures of the Discourse Analysis in studies performed by Eni Orlandi. These studies are dedicated to explore the concepts developed by Michel Pêcheux such as discursive formation, interdiscourse, subject and interpretation. Orlandi is also considered one of the founders of the so-called Discourse Analysis, which has become a discipline in various post-graduate programs and some undergraduate courses in Brazil. After presenting the review, we illustrate the analytical procedure with a brief analysis of a parallel discourse, which is part of the novel A mulher que fugiu de Sodoma, written by José Geraldo Vieira.

Keywords: Analytical Procedures. Discourse. Novel.

\section{A metodologia da pesquisa em Análise de discurso}

Entre as diversas vertentes de estudo em Análise de discurso (doravante AD), optamos por resenhar os procedimentos metodológicos da denominada "Análise de Discurso francesa", filiada ao pensamento de Michel Pêcheux, com ênfase na resenha dos textos de Eni Orlandi.

$\mathrm{Na}$ introdução à segunda edição de Orlandi (1987, p. 11), a autora defende que a teoria, o objeto e o método científicos da AD são moldados em uma dimensão crítica, o que dificulta "um acúmulo científico fixo". Esse jogo de idas e vindas entre teoria, objeto e métodos permanece ainda hoje nesse domínio de estudo. No entanto, o academicismo e a entrada maciça da $\mathrm{AD}$ em programas de pós-graduação, bem como diferentes propostas de sua utilização em espaços escolares, exigem um maior rigor metodológico e didático.

O principal objetivo deste texto é, dentro das possibilidades que permitem tal domínio de pesquisa, estabelecer alguns parâmetros metodológicos para quem pretenda realizar uma análise de discursos constitutivos de romances. Para atingir esse objetivo, faremos uma resenha do que a $\mathrm{AD}$ propõe como procedimentos metodológicos de análise.

Eni Orlandi (1987), em texto publicado originalmente em 1977, afirma que o seu procedimento analítico segue "o seguinte percurso: análise de palavras; análise de construções; construção de uma rede semântica, intermediária entre o social e o gramatical; consideração da produção social do texto como constitutiva de seu sentido." (ORLANDI, 1987, p. 57-58).

Por essa proposta metodológica, o analista deverá associar gramática (língua e texto), discurso e sociedade. Não há uma clareza sobre o objeto de estudo, que se caracterizaria como uma zona mista de língua, texto e discurso. No entanto, o percurso é bem claro: parte-se da

\footnotetext{
* Professor Adjunto da Unidade Acadêmica de Letras (UAL) da Universidade Federal de Campina Grande (UFCG). Endereço eletrônico: alodanta@yahoo.com.br
} 
base - a língua -, atravessa-se o texto, para se chegar ao discurso, caracterizado como uma produção social. Como podemos perceber, é bem o início da AD.

Em um outro artigo, publicado originalmente em 1981, a autora repete esse mesmo procedimento em níveis, mas procurando delimitar melhor o objeto de estudo. A análise acontecerá em três níveis: o contexto linguístico (estruturação de frase), contexto situacional (estruturação de enunciados) e a consideração da unidade texto em seu processo de significação (ORLANDI, 1981, p. 59-60). Nessa proposta metodológica, temos o que a autora denomina de "unidade" de estudo, que deixa de ser a soma de frases e ganha uma outra natureza, ou seja, passa a ser discurso, o que o analista só percebe com o auxílio do conceito de funcionamento discursivo, definido pela autora como uma "atividade estruturante de um discurso determinado, por um falante determinado, para um interlocutor determinado, com finalidades específicas" (ORLANDI, 1981, p. 61, grifos da autora). O objeto de estudo ganha mais espessura, embora os procedimentos analíticos ainda permanecem vagos e obscuros.

Em outro artigo de 1981, Eni Orlandi afirma que, metodologicamente, "pode-se trabalhar, na perspectiva da análise de discurso, com unidades de vários níveis - palavras, sentenças, períodos, etc. - sob o enfoque do discurso" (ORLANDI, 1981, p. 116). Por essa afirmação, entendemos que o olhar discursivo atravessa toda e qualquer realidade da linguagem. Em consequência, a autora estabelece uma distinção em seu objeto de estudo: "discurso é conceito teórico e metodológico e texto é conceito analítico" (ORLANDI, 1981, p. 116). Essa distinção entre texto e discurso, que ainda hoje podemos utilizar sem prejuízo para a análise, é um passo importante para a compreensão e a descoberta de procedimentos analíticos em AD.

Ainda em 1981, a autora introduz uma nova delimitação do objeto de pesquisa em $\mathrm{AD}$, o recorte textual: "o recorte é uma unidade discursiva: fragmento correlacionado de linguagem - e - situação. O texto é o todo que organiza os recortes (...). Os recortes são feitos na (e pela) situação de interlocução" (ORLANDI, 1981, p.140, grifos do autor). A noção de objeto empírico - os recortes do texto - adquire uma noção própria de rigor metodológico, permitindo ao pesquisador selecionar da vastidão de seu corpus aquelas variáveis relacionadas às condições de produção da pesquisa.

Nesse primeiro momento, a AD tem um objeto teórico - o discurso - e um objeto empírico - o texto, do qual são seccionados, em conformidade com a situação de interlocução discursiva e as condições de produção da pesquisa, os recortes, que são, efetivamente, uma construção metodológica do pesquisador, em consonância com o discurso, seu objeto teórico.

Em outro artigo, originalmente de 1984, a autora (ORLANDI, 1988, p. 15-16) retoma essa oposição entre objetos, distinguindo-os em dado empírico e objeto científico, afirmando que há uma relação entre objeto, técnicas de análise, metodologia e teoria. Ela explicita o que é o objeto discurso e como os princípios teórico-metodológicos da AD podem esclarecê-lo. Ao mostrar como se relacionam as técnicas e o objeto de análise, retorna à distinção, já mencionada anteriormente, entre discurso e texto: "a relação entre o discurso e o texto é a que existe entre o objeto teórico e o da análise (...) o objeto teórico é o discurso e o objeto empírico (analítico) é o texto" (ORLANDI, 1988, p. 21). Considera também o recorte, na medida em que, para o texto tornar-se unidade de discurso, ele adquire as seguintes características: passa de segmento a recorte, o recorte é a relação das partes com o todo, tem uma natureza heterogênea, relaciona-se com o não-dito, a incompletude e a situação de interlocução (ORLANDI, 1988, p. 22).

Esse esforço de rigor metodológico ainda deixa em branco o que são as técnicas de análise, ou, em termos mais simples, o artigo não nos apresenta caminhos de como analisar recortes textuais, fora de conceitos ideologicamente preparados por um objetivo prévio. 
Em outro texto, Orlandi (1990) defende que, em termos metodológicos, a AD critica as outras disciplinas (a linguística, por exemplo), construindo, nessa crítica, seus procedimentos e seu objeto, demarcando seu território. A autora não explicita, na seção denominada "em torno do método e do objeto", a natureza prático-analítica dos "procedimentos" referidos, elaborando seu texto em torno dos conceitos operatórios de análise, como sujeito, interdiscurso e sentido, no entanto nos dá uma luz sobre a relação entre compreensão e interpretação, operações primordiais para qualquer procedimento analítico:

A compreensão é teórica e a interpretação é ideológica. Isto é, a interpretação trata da atribuição de sentidos determinados por posições " $x$ " ou "y". Ela já se dá no interior do jogo de sentidos de uma FD determinada: na relação de formações discursivas, interpreta-se uma pela outra, definindose os seus limites. Na compreensão dos sentidos, ao contrário, apreende-se esse jogo das formações discursivas e da delimitação dos seus bordos: compreender é saber que o sentido pode ser outro (ORLANDI, 1990, p. 252).

Embora não esteja dito explicitamente, essa distinção entre interpretação e compreensão é um passo fundamental para o estabelecimento de um procedimento analítico em $\mathrm{AD}$ e será desenvolvido, de modo mais aprofundado, em outro livro da autora.

Em todo um capítulo, ela apresenta o modo de como transformar a noção de interpretação em um dispositivo analítico (ORLANDI, 1996, p. 79-98). Ela parte do aproveitamento metodológico de dois conceitos, o funcionamento e a metáfora (efeito metafórico). Por meio do primeiro, o analista deve "explicitar os mecanismos de funcionamento do discurso", mostrando como "os processos de significação trabalham um texto"; o uso do conceito de efeito metafórico permitirá ao pesquisador analisar/descrever os deslizamentos e transferências de sentido, que produzem equívocos no discurso (ORLANDI, 1996, p.80).

A ferramenta metodológica de que se lança mão para a análise do funcionamento discursivo e dos efeitos metafóricos de deslocamento e equívoco é a interpretação, definida pela autora como "um 'gesto', um ato no nível simbólico (...) marcado pela incompletude, pela relação com o silêncio (...) é o lugar próprio da ideologia e é 'materializada' pela história" (ORLANDI, 1996, p. 18). Como a própria autora enfatiza, "o trabalho da interpretação, enquanto efeito metafórico e deslize de sentidos, é o lugar onde língua e história se ligam pelo equívoco", o que enriquece o dispositivo analítico do sujeito, pois permite a este estar atento à ausência necessária, o que não se diz, mas ecoa no discurso. Nesse sentido, a autora defende que a "interpretação do analista (metodológica) tem de levar em conta o movimento da interpretação inscrita no próprio sujeito do discurso" (ORLANDI, 1996, p.82-83).

O gesto de interpretação, segundo a autora, divide-se em dois: o dispositivo teórico do analista e o dispositivo ideológico como evidência para a forma-sujeito histórica. $\mathrm{O}$ dispositivo teórico deve permitir que "o analista trabalhe as fronteiras das formações discursivas", enquanto o dispositivo ideológico dos sujeitos comuns apaga a presença da alteridade e da historicidade e evidencia os sentidos como naturais (ORLANDI, 1996, p. 8485). Não se pretende produzir um procedimento analítico que estabeleça pontos estruturais de fechamento do texto, mas "mostrar a relação da posição do analista com os gestos de interpretação do sujeito", através da descrição de "montagens discursivas" (ORLANDI, 1996, p. 87).

Vamos ouvir o que diz a autora em relação à sua proposta de procedimento analítico: 
A vantagem que vejo em um dispositivo analítico com o que temos proposto no campo teórico da análise de discurso é que, como não trabalhamos só com a estrutura mas também com o acontecimento da linguagem, esses aspectos que tocam o acaso, o equívoco e a forma histórica da interpretação são levados em conta na compreensão de cada gesto de interpretação (ORLANDI, 1996, p. 98).

Nesse momento, temos um grande avanço, em termos metodológicos, na $\mathrm{AD}$, se considerarmos que não estamos mais nos restringindo apenas à definição do objeto de estudo.

Em outro texto, a autora reforça a presença da interpretação na $\mathrm{AD}$ como dispositivo de análise, enfatizando que "descrição e interpretação se interrelacionam", definindo os dois momentos da análise em que aparece a interpretação: a interpretação é parte do objeto de análise, pois o sujeito comum e o analista usam gestos de interpretação; e a descrição de uma montagem discursiva inclui a interpretação na escolha de um dispositivo teórico (ORLANDI, 1999). O dispositivo analítico sustenta-se pela mediação teórica e particulariza-se, para o analista, em função das seguintes etapas metodológicas: a) a questão que o analista faz ao seu material de análise (o corpus); b) o domínio científico a que ele vincula sua pesquisa; c) os resultados a que ele pode chegar com seu dispositivo analítico de descrição e interpretação (cf. ORLANDI, 1999, p. 62).

A autora afirma que o primeiro passo para uma análise "é a constituição do corpus", que é delimitado, não por critérios empíricos, mas teóricos. Distingue-se em experimentais e arquivo e envolve "práticas discursivas de diferentes naturezas: imagem, som, letra, etc." A $\mathrm{AD}$ não exige a exaustividade horizontal do corpus, pois "não há discurso fechado em si mesmo, mas um processo discursivo do qual se podem recortar e analisar estados diferentes", mas exigem uma exaustividade vertical, "considerada em relação aos objetivos da análise e à sua temática" (ORLANDI, 1999, p. 62-63). A AD descarta a consideração dos elementos da linguagem como "dados" e considera-os como fatos linguístico-discursivos.

Por essas características, devemos concordar com a autora quando ela conjuga os procedimentos analíticos e os princípios teóricos, já que a seleção dos textos para análise é inseparável das proposições e conceitos teóricos da AD. Por exemplo, se pretendemos analisar, em termos de $\mathrm{AD}$, um romance, este, não visto mais com os mesmos óculos da teoria da narrativa, na qual são essenciais conceitos como narrador, personagem, intriga, foco narrativo, mas será caracterizado como uma prática discursiva realizada por um sujeito (escritor ou autor?), que produz um efeito discursivo de real, através do qual outros sujeitos assumem discursos (vozes, personagens?) que, muitas vezes, são paralelos ou subalternos em relação ao discurso autoral ou à temática do romance. Daí, concordarmos com a indissolubilidade de objeto, teoria e análise proposta pela autora, como, com outras palavras, está dito abaixo:

a construção do corpus e a análise estão intimamente ligadas: decidir o que faz parte do corpus já é decidir acerca de propriedades discursivas (...) a melhor maneira de atender à constituição do corpus é construir montagens discursivas que obedeçam critérios que decorrem de princípios teóricos da análise de discurso, face aos objetivos da análise, e que permitam chegar à sua compreensão (ORLANDI, 1999, p. 63).

A autora especifica um pouco mais a sua proposta de procedimento analítico em uma outra seção desse livro de 1999, quando estabelece três etapas de análise, as quais podemos visualizar no quadro abaixo: 
Quadro 1: Etapas de análise

\begin{tabular}{|l|l|l|l|}
\hline $1^{\text {a }}$. Etapa & Passagem da & Superfície Linguística para o & Texto (Discurso) \\
\hline $2^{\text {a }}$. Etapa & Passagem do & Objeto Discursivo para o & Formação Discursiva \\
\hline $3^{\text {a }}$ Etapa & & Processo Discursivo & Formação Ideológica \\
\hline
\end{tabular}

O analista deve fazer o tratamento do texto, de modo a resgatar, de sua enunciação, os diferentes processos discursivos, tarefa que apenas será realizada, na segunda etapa, quando o analista confronta as relações entre diferentes formações discursivas "com a formação ideológica que rege essas relações" (ORLANDI, 1999, p. 77-78). Essas etapas só se realizarão com o auxílio de dois processos discursivos: a paráfrase (sinonímia, relação do dito com o não-dito) e o efeito metafórico (substituições, deslizes e equívocos). Esses processos discursivos articulam estrutura e acontecimento, no interior da relação da língua com o discurso.

Em sua materialidade, a análise discursiva está envolvida constantemente com a escrita e esta precisa ser situada metodologicamente. Eni Orlandi (2001) divide a escrita da $\mathrm{AD}$ em escrita teórica - que não se filia a uma Linguística Formal, e escrita analítica centrada no modo como a análise é lida e exposta ao leitor. Essa escrita aceita a relação sujeito, linguagem e história ("a linguagem não é transparente"), a presença da ideologia e o confronto do simbólico com o político (ORLANDI, 2001, p. 31). Essa escrita é uma ciência, com procedimentos analíticos (relação entre prática e teoria), com objeto próprio (o discurso), com unidade de análise (o texto), com pressupostos teóricos (disciplina AD) e com resultados próprios. Do ponto de vista metodológico, trabalha os limites da interpretação na articulação entre o dispositivo teórico e o dispositivo analítico (ORLANDI, 2001, p. 32).

$\mathrm{O}$ analista de discurso precisa conscientizar-se de que encontra no campo de uma ciência - a $\mathrm{AD}$ - que "não acumula teoricamente, ao estilo das ciências positivas. Ela reinscreve as questões no âmbito mesmo da definição de seu objeto a cada movimento das diferentes práticas analíticas" (ORLANDI, 2001, p. 36). Essa escrita da prática analítica, em constante movimento, desenvolve a teoria em sua historicidade, situando-a, nas diferenças em suas relações com outras ciências em geral e com as da linguagem (Pragmática, Semântica da Enunciação).

Em suma, a escrita de AD tem algumas propriedades que precisam ser respeitadas: a) deve textualizar a relação descrição e interpretação; b) deve tornar sensível, para o sujeito, o interdiscurso (a memória) e a constitutividade histórica desse sujeito em sua relação com o simbólico; c) deve formular a possibilidade da interpretação em um dispositivo analítico; d) não deve ser pré-fabricada, pronta, mas uma prática constante que devolve o texto a seu processo social e histórico; e) deve questionar as diferentes maneiras de ler (cf. ORLANDI, 2001).

Assim concebida, a AD constitui-se em uma ciência que coloca o próprio trabalho da escrita como uma ferramenta de seu quadro metodológico, o que traz fortes consequências para o estudo da linguagem, entre as quais, podemos citar a necessidade de que o discurso se constitui em uma prática simbólica e a de que a leitura é um trabalho. Como afirma a autora que estamos resenhando, mesmo que o objeto da $\mathrm{AD}$ não seja a língua, esta é considerada como pressuposta, na media em que "o analista de discurso tem de saber como a língua é para que funcione como funciona" (ORLANDI, 2004, p. 18). Em outras palavras, uma análise de discurso precisa compreender os mecanismos de significação que engendram os discursos e, para tanto, deve estudar a língua, mas como um lugar de equívocos e falhas. 
É necessário que seja explicitado, de modo mais concreto, o que vem a ser o procedimento analítico da $\mathrm{AD}$ :

a noção de dispositivo tem um sentido preciso que leva em conta a materialidade da linguagem, em outras palavras, sua não transparência, e coloca a necessidade de um 'instrumento teórico' para se ter acesso a ela, para trabalhar sua espessura semântica - linguística e histórica - em uma palavra, a discursividade. A Análise de Discurso é a disciplina que vem ocupar o lugar dessa necessidade teórica trabalhando a opacidade do dizer e vendo nessa opacidade a intervenção do político, do ideológico, ou seja, o fato mesmo do funcionamento da linguagem: a inscrição da língua na história para que ela signifique (ORLANDI, 2004, p. 20).

Esse dispositivo analítico, como repetido nesse texto, conjuga teoria e procedimento analítico, sem esquecer que o objetivo do analista é descrever o funcionamento do texto (objeto simbólico) e mostrar os processos de significação da discursividade desse texto (ORLANDI, 2004, p. 22), portanto, deve haver um balanceamento ou equilíbrio, na análise, entre descrição e interpretação. A construção do dispositivo analítico "desloca a posição do sujeito para uma posição enquanto lugar construído pelo analista” (ORLANDI, 2004, p.23). Nesse sentido, o próprio objeto teórico - a discursividade encontrada no texto - é um lugar, ou um efeito de sentido, construído pelo analista.

Em diferentes momentos sugere-se que a AD é uma disciplina de entremeio, mas o que vem a ser entremeio? Eni Orlandi define entremeio como uma atividade que pratica a perspectiva de pensar, o que denominaremos de relações entre (semântica geral ou enunciativa e semântica discursiva, língua como real e contradições das discursividades, diferentes efeitos de sentido, psicanálise e análise de discurso). Esse método de entremeio apresenta as seguintes características: a) não pensar relações hierarquizadas (instrumentalizadas, aplicações), mas a transversalidade das disciplinas; b) é um método aberto, dinâmico (não positivista); c) sem aplicação automática da teoria, mas com mediação entre teoria e prática, pesquisando procedimentos próprios ao objeto que se analisa, através da interrogação e do confronto. Por essas características, vê-se que, como afirma a autora, "a análise de discurso é, antes de tudo, análise" (ORLANDI, 2012, p. 12).

Eni Orlandi (2012) propõe uma nova virada para a AD, em razão das novas concepções de ciência e nova conjuntura histórica na contemporaneidade, mas também, e principalmente para este nosso texto, em razão do novo tipo de análise e de noções da AD. Esse tipo de análise deve incluir os conceitos centrais de interdiscurso e metáfora/metonímia (ORLANDI, 2012, p. 41). Esse tipo de análise efetua-se pelo interdiscurso, quando "elementos de uma formação discursiva são metaforizados (metonimizados) de uma para outra formação discursiva de forma que as referências discursivas podem se construir e se deslocar historicamente" (ORLANDI, 2012, p. 51).

\section{Procedimento analítico para romances}

Em razão do que foi exposto na seção anterior, precisamos reconstituir de modo sumário o percurso metodológico da $\mathrm{AD}$, para em seguida procurarmos caminhos para uma análise dos discursos em romances.

A $\mathrm{AD}$, em termos metodológicos, deve conter um corpus, que se subdivide em objeto empírico (texto) e objeto teórico, uma teoria, uma pergunta de pesquisa do analista, 
procedimentos analíticos, etapas de análise e resultados. Ilustraremos de modo detido a construção do corpus e, em sua análise, deixamos implícitos os elementos seguintes.

A construção do corpus inicia-se com a decisão do pesquisador de não vê-lo como "dados", mas como fatos de linguagem. Esse fato tem como objeto empírico, ou unidade de análise, o texto. No entanto, esse texto não entra como unidade bruta, mas recebe um tratamento teórico, que o transforma no objeto teórico, construído pelo analista, condicionado por suas perguntas de pesquisa ou seus objetivos. Selecionado esse objeto teórico, o texto será transformado em recortes textuais, em razão do objeto teórico e de seus condicionamentos sócio-históricos. Selecionados os recortes textuais, o analista especificará melhor o seu objeto teórico, selecionando as sequências discursivas que melhor explicitam a pergunta de pesquisa do analista, em relação ao seu objeto teórico, o discurso. Consequentemente, o corpus da AD é um complexo que abrange textos, recortes textuais, discurso e sequências discursivas.

Vamos nos servir de um romance de José Geraldo Vieira como laboratório e demonstração dessa metodologia de AD. O romance é A mulher que fugiu de Sodoma, que teve sua primeira edição em 1931. Deixando de lado a sua trama narrativa - que está brevemente resumida no Anexo 1 - concentremo-nos em analisar-lhe o discurso. Estamos diante de um texto literário de grande riqueza discursiva: a narrativa bíblica sobre Sodoma e Gomorra, o discurso moralista católico, o acontecimento discursivo do vício de jogo, o discurso da arte, o discurso sobre a profissão de médico, o discurso sobre a mulher. Todos esses discursos são centrais na narrativa, mas há um discurso paralelo, que é iniciado, mas não desenvolvido pelo autor e que se presta a uma análise de discurso: o discurso sobre a identidade da professora. Uma análise desse romance, pelo viés da $\mathrm{AD}$, deve começar por estabelecer todos os recortes textuais, que se referem à professora. Como essa seção é apenas uma amostragem e não uma análise completa, serão citados apenas dois:

Uma criança veio espreitar na porta. Sorriu ao ser surpreendida e fugiu.

- É a minha filha. "Vai agora estudar piano, minha filha, vai. São horas." Calcula que não consigo convencer Nuno que a devemos pôr num colégio. A preceptora vai regressar para a Suíça, temos que procurar outra. É tão difícil. Nem Nuno nem podemos suportar a ausência dela um dia, imagina tu... De maneira que ela vai estudando mesmo em casa. É uma porção de horários, eu a acho fraca e nova para começar tão cedo, mas Nuno exige. Tem professora de várias coisas. A preceptora é quase uma figura dispensável. Às vezes eu assisto, também, às aulas. Vou, sem querer, recordando episódios de história, nomes de ilhas, cabos e penínsulas, datas, lugares de batalhas. Para que se há de querer meter naquela cabeça tanta coisa passada, inútil, não é? Mas a minha filha apreende tudo, decora tudo, sabe mais do que eu. (VIEIRA, 2008, p. 59)

Realmente [Nuno de Almada] chegou, falando com o Moreira, subiu, desceu logo e, ao cumprimentar Lúcia, foi dizendo, ao passo que se sentava:

- O essencial, desde logo, será a senhora conseguir tirar a pronúncia de Pindamonhangaba de minha filha Leonor. A Eusébia viciou-se a dizer "poilta" em vez de "porta" e "Jundiail" em vez de "Jundiaí". E isso é um horror. - A filha, ao ouvir, tapou a cara, rindo. (VIEIRA, 2008, p.168)

Evidentemente que o conjunto de recortes textuais, em uma análise completa, seria bem maior, no entanto como o objetivo desse artigo é apenas mostrar como se utilizar do procedimento analítico da AD nos discursos que constituem romance, nos concentraremos nesses recortes. Identificados os recortes textuais, qual o objeto discursivo que atende à questão da pesquisa, qual a identidade da professora na década de 1920 ? Temos assim o 
objeto teórico, que é a identidade da professora, e mais dois objetivos que o analista perseguirá: descrever como eram nomeadas essas profissionais e interpretar as razões políticas da natureza feminina dessa profissão. As respostas à pergunta e a análise do funcionamento discursivo pressuposto nos objetivos encaminham o pesquisador às seguintes sequências discursivas, que é o material que será analisado, que devem receber um tratamento formal:

Sd1A preceptora vai regressar para a Suiça, temos que procurar outra.

$\mathrm{Sd} 2 \mathrm{Tem}$ professora de várias coisas. A preceptora é quase uma figura dispensável.

$\mathrm{Sd} 3$ Ás vezes eu assisto, também, às aulas.

$\mathrm{Sd} 4$ O essencial, desde logo, será a senhora conseguir tirar a pronúncia de Pindamonhangaba de minha filha Leonor.

No tocante à questão que o analista faz ao objeto discursivo, verificamos na Sd1 uma distopia na identidade da professora, no sentido de que ela não tem um lugar na sociedade carioca da época, o que é marcado pelas formas verbais vai regressar e procurar. A professora é um lugar social vazio, por onde passeiam diferentes sujeitos (empregados que regressam e patrões que procuram). Já $\mathrm{Sd} 2$ mostra discursivamente as diferentes nomeações da professora: professora e preceptora. Esses nomes ora marcam formações discursivas diferentes (professora = operária; preceptora = coordenadora), ora marcam a mesma formação discursiva, por um efeito metafórico de sinonímia. Quando a professora é operária exerce muitas funções (várias coisas), enquanto a preceptora, só não é dispensável, porque coordena (é o que permite a análise de quase). O efeito metafórico/metonímico de substituição sinônima só poderá ser analisado em outros recortes textuais do romance, que não escolhi em razão do exíguo espaço textual deste artigo.

As sequências discursivas $\mathrm{Sd} 3$ e $\mathrm{Sd} 4$ remetem para a conjuntura política da década de 1920, referentemente ao fato de que as mulheres exerciam a função de professora e/ou preceptora. É uma sociedade na qual os homens detêm o poder, reservado à mulher o papel de execução das ordens do homem. Em Sd3, Ana Maria, a esposa do milionário Nuno de Almada, assiste às aulas que a filha recebe, com um certo sentido de obediência ao marido, para exercer sua função de mãe, ou seja, ela não assiste à aula porque tem críticas a fazer à professora, mas porque naquela sociedade ela só tinha o direito de ser mãe, por essa razão devia acompanhar a filha, inclusive em suas tarefas escolares, embora tivesse professora particular. Já a Sd4 é um discurso de ordem, no qual o milionário exige da nova professora que ela elimine os vícios de linguagem da filha. Esse discurso imperativo (modalizado e levemente atenuado como meta na forma verbal conseguir tirar) é uma marca dos homens de elite da época, reiterando homens que detêm o poder. O resultado da pesquisa é a própria escrita da análise, que desloca o sujeito comum em sujeito analista, o que traz implicações para o leitor, que se converte em um sujeito analista que adentra o mundo discursivo do romance. Transportada para a escola, essa leitura pode fazer o aluno pensar criticamente o que é ser professor, somando aos recortes textuais do romance, outros recortes, advindos da mídia impressa (notícias e reportagens sobre professores), virtual (blogs e redes sociais que discutem a condição docente) e da ciência da educação.

\section{Considerações finais}

Esperamos que, com a pequena análise ilustrativa, tenhamos demonstrado que o procedimento analítico de $\mathrm{AD}$ em romances considere inicialmente, no interior da dispersão textual de um romance, recortes textuais e sequências discursivas, momento em que se 
coaduna a consistente relação entre teoria e prática, descrição e interpretação (procedimento analítico central da AD) e permita a elaboração de questões e objetivos de pesquisa, com as etapas de análise, que transformam o texto em objeto discursivo, numa análise dos processos discursivos ideológicos. Esse procedimento analítico permite que o pesquisador de discursividades, respeitando a sua natureza interrogativa e crítica, faça uma montagem discursiva que abranja diferentes gêneros textuais, de diferentes domínios discursivos, como a mídia, o político, o jurídico, o literário, o religioso e de diferentes suportes, como o visual, o auditivo, o cinésico (cinema, música, dança), bem como o virtual (blogs, redes sociais, $e$ mails). Mas sem esquecer a escrita, que, em AD, é teórica e analítica.

\section{Referências}

ORLANDI, E. P. A linguagem e seu funcionamento: as formas do discurso. Campinas: Pontes, 1987.

. Discurso e leitura. São Paulo: Cortez; Campinas: Edunicamp, 1988.

- Terra à vista: discurso do confronto: velho e novo mundo. São Paulo: Cortez; Campinas: Edunicamp, 1990.

1996.

Interpretação: autoria, leitura e efeitos do trabalho simbólico. Petrópolis: Vozes,

Análise de discurso: princípios e procedimentos. Campinas: Pontes, 1999.

Discurso e texto: formulação e circulação dos sentidos. Campinas: Pontes, 2001.

. Cidade dos sentidos. Campinas: Pontes, 2004.

Discurso em análise: sujeito, sentido, ideologia. Campinas: Pontes, 2012.

\section{Anexo 1}

VIEIRA, J. G. A mulher que fugiu de Sodoma. Belo Horizonte: Leitura, 2008.

A cidade é o Rio de janeiro e o período abrange o espaço de 1923 a 1925. Mário Montemor é um médico viciado em jogo, que se utiliza do dinheiro de um colega para jogar e perde-o todo. Sua esposa, Lúcia, consegue recuperar o dinheiro com uma colega de escola, Ana Maria, a esposa do milionário Nuno de Almada. Abandona o marido e vai viver com a tia, até que sua ex-colega convida-a para ser preceptora de sua filha Leonor. Enquanto isso, Mário recorre a um tio, rico fazendeiro de café, ex-ministro, que vive em Ribeirão Preto. O tio lhe dá uma pensão (ele também recebe uma outra, cuja fonte ele não conhece, mas o leitor fica sabendo que é doada por Nuno de Almada) e exige que ele vá fazer uma especialização médica em Paris. Durante o primeiro ano, Mário é um assíduo frequentador do curso e do hospital, mas depois que conhece uma modelo de pintor, Pervanche, ele decide alugar um apartamento mais luxuoso e volta a conviver com o vício de jogar, agora em corrida de cavalos. Desleixa o curso, aumenta os gastos e termina por se endividar. O acúmulo de dívidas, a morte do tio, a suspensão das duas pensões (a do tio e a de Nuno de Almada) atiram-no ao abandono nas ruas de Paris, sujeito aos rigores do inverno. De imediato adquire 
uma tuberculose, que lhe causa a morte. Nesse mesmo período, Lúcia está vivendo no luxo da casa dos Almada, sempre resistindo ao assédio do marido da colega de infância. Ao descobrir que Nuno de Almada escondera uma carta de Mário, enviada de Paris, descoberta simultânea à de que o marido falecera, sofre de remorsos por ter abandonado o marido e decide "fugir" da Sodoma, metaforizada pela casa do milionário. O título se justifica em três sentidos: o projeto de quadro que seria de Rubens, intitulado A mulher que fugiu de Sodoma; a fuga de Lúcia do vício de jogo do marido; e a fuga de Lúcia da sedução da riqueza e da sensualidade que lhe acompanha, na figura do marido de Ana Maria. A primeira edição deste romance é de 1931.

Recebido em: agosto de 2013.

Aprovado em: setembro de 2013. 